\title{
Pulling out a broken catheter using interventional radiology in a preterm. Neonatal intensive care
}

\author{
Ismael José Dorta Luis, ${ }^{1}$ Paloma González Carretero, ${ }^{2}$ Carmen Luz Marrero Pérez, 2 \\ Ignacio Hernández Cabezudo, ${ }^{3}$ Antonio López Figueroa, ${ }^{4}$ Andrea González Palau1 \\ ${ }^{1}$ Department of Pediatrics; ${ }^{2}$ Department of Neonatology; ${ }^{3}$ Department of Radiology; ${ }^{4}$ Department of Pediatric \\ Radiology, Nuestra Señora de Candelaria University Hospital, Santa Cruz de Tenerife, Spain
}

\begin{abstract}
There are different indications for the placement of a pleural drainage. It is indicated in a massive pneumothorax or a pleural effusion, and a tunnelled indwelling pleural catheter is put in place. As in any procedure, complications may occur. A broken catheter is a rare one, and when it occurs, it has to be removed by thoracoscopic surgery. This article describes the first case of a removal of a fractured pleural catheter in a preterm newborn with a bilateral pneumothorax using interventional radiology. We propose an alternative way less invasive that could enable a shorter recovery time with fewer complications.
\end{abstract}

\footnotetext{
Correspondence: Ismael José Dorta Luis, Department of Pediatrics, Nuestra Señora de Candelaria University Hospital, Carretera del Rosario 145, 38010, Santa Cruz de Tenerife, Spain. Tel.: +34922602154.

E-mail: ismael2195@gmail.com,
}

Key words: Neonatology; preterm; pleural drainage; intensive care; interventional radiology.

Conflict of interest: The authors declare no conflict of interest.

Availability of data and materials: All data underlying the findings are fully available.

Ethics approval and consent to participate: No ethical committee approval was required for this case report by the Department, because this article does not contain any studies with human participants or animals. Informed consent was obtained from the guardians of the patient included in this study.

Consent for publication: The patient's guardians gave written consent to use the patient's personal data for the publication of this case report and any accompanying images.

Received for publication: 26 February 2021.

Accepted for publication: 20 April 2021.

This work is licensed under a Creative Commons Attribution

NonCommercial 4.0 License (CC BY-NC 4.0).

OCopyright: the Author(s), 2021

Licensee PAGEPress, Italy

La Pediatria Medica e Chirurgica 2021; 43:255

doi:10.4081/pmc.2021.255

\section{Introduction}

There are different indications to perform a pleural drainage. Thoracentesis is a procedure where the pleural space is accessed by a needle or a catheter, either for diagnostic purposes; obtaining liquid to analyze, or therapeutic; liquid or air drainage accumulated internaly. In some cases of pleural effusion or massive pneumothorax, it is necessary to have a tunnelled indwelling pleural catheter (TIPC) ${ }^{1-3}$ put in place.

Some complications related to the procedure can occur, such as the output of the catheter, subcutaneous emphysema, hemorrhage due to laceration of the rib vessels, infection, pulmonary edema, obstruction of the catheter, or the damage of organs, diaphragm or catheter. ${ }^{1-3}$ A broken catheter is a fairly infrequent complication. It does occur usually during its extraction. ${ }^{4-6} \mathrm{We}$ describe the first case of a removal of a fractured pleural catheter in a preterm newborn using interventional radiology.

\section{Case Report}

We present the case of a preterm newborn $(32+4$ weeks $)$, birth weight 2300 grams (p50-90). She is admitted to the neonatal intensive care unit with a clinical suspicious diagnosis of grade IIIII hyaline membrane disease. She required two doses of endotracheal surfactant in the first 24 hours of life using minimally invasive surfactant therapy, known as MIST.?

The second day of life she showed a sudden clinical worsening and she required intubation and connection to invasive mechanical ventilation. She had a bilateral pneumothorax, which required a TIPC to be placed for a pleural drain (pleurocath 6 fr) with a beveled trocar, using the Seldinger technique. As an incident during the procedure occurred, the intrapleural catheter was ruptured and migrated inside the pleural cavity (Figure 1). We postulate it could have happened due to not introduce the trocar while the TIPC was being manipulated for relocation. Due to instability, extraction of the broken catheter was postponed until recovery. During her admission, she presented a left diaphragmatic paralysis due to a lesion of the phrenic nerve secondary to the placement of the thoracic drain and the time that remained inside.

Three weeks later, it was removed using interventional radiology. For this, a percutaneous approach was chosen using regional anesthesia, accessing through the mid-axillary line.

We get into the pleural cavity guided by ultrasound. We introduced a vascular catheter ( $6 \mathrm{~F}$ introducer) with a valve, avoiding 
pneumothorax during manipulation. It was tried to recover with a proximal loop (Figures 2 and 3), after with a distal loop, both without success, and when it was confirmed that the fibrin adherence prevented the loop from passing to capture the catheter, it was tried to solve it with a rotation of a vascular catheter with a pigtail curve around it (Figure 4).

None of these were effective, so it was taken advantage of the access to the pleura and it was used to put into an Adson tweezers with teeth pulling out the broken catheter (guided by direct scope) without an incident (Figure 5 and 6). The patient evolves favorably, recovering diaphragmatic mobility in the following days.

\section{Discussion}

The extraction of a migrated catheter is typically performed by thoracoscopy or thoracotomy. ${ }^{3}$

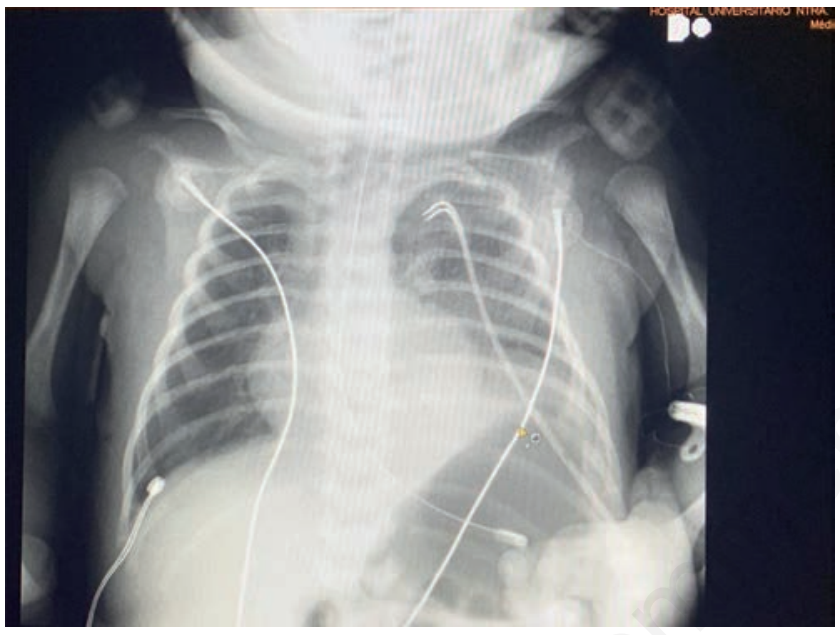

Figure 1. Chest $\mathrm{x}$-ray. Fractured catheter placed in left thorax.

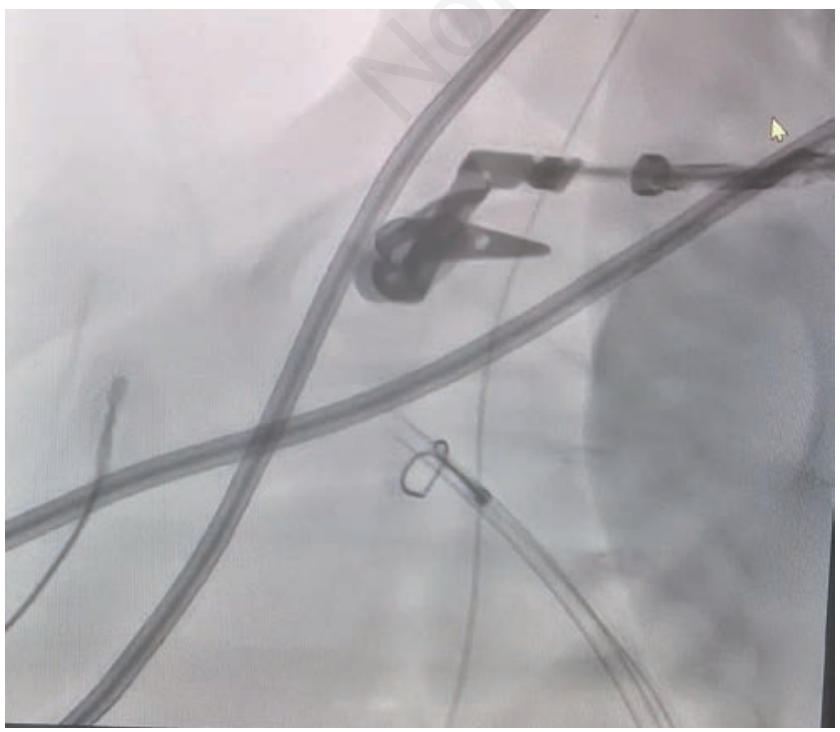

Figure 2. Proximal loop.
The possible complications are assumed by physicians. There are few absolute contraindications to perform a thoracoscopy, the main being the absence of a pleural chamber due to an abundance of flanges that will prevent the introduction of the thoracoscope. In patients who cannot tolerate one-lung ventilation; as is our case, a premature infant with moderate-severe hyaline membrane, the performance of this technique is discarded. The most common complications of a thoracoscopy are: subcutaneous emphysema and pain. Carrying out a thoracoscopy for the removal of the thoracic drainage would hardly lead to other less frequent complications

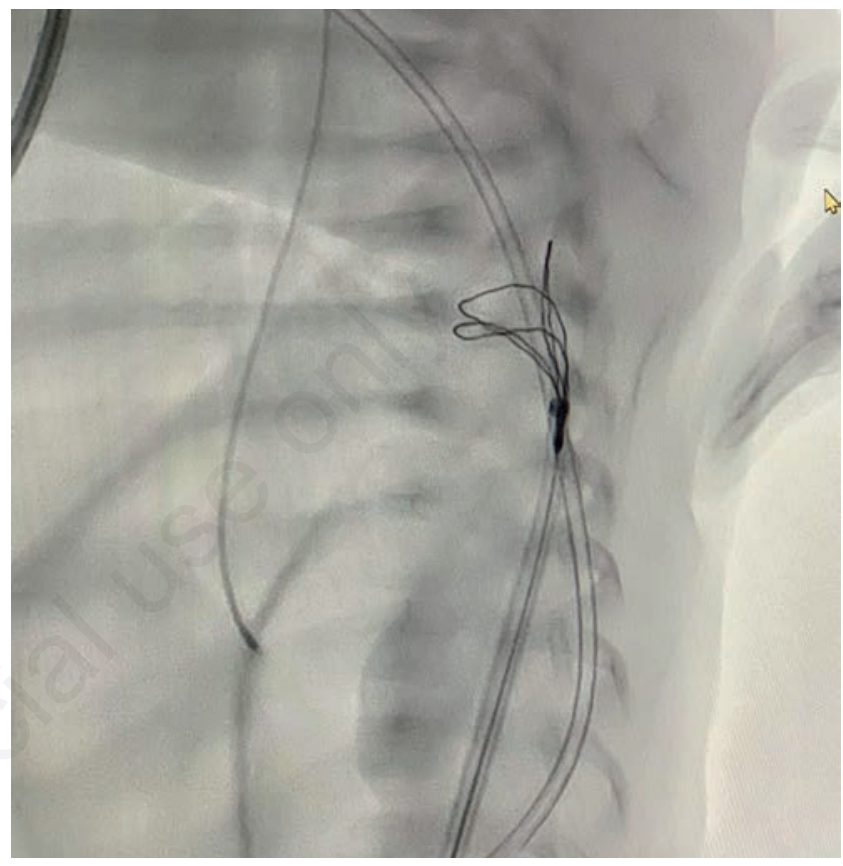

Figure 3. Proximal triple loop.

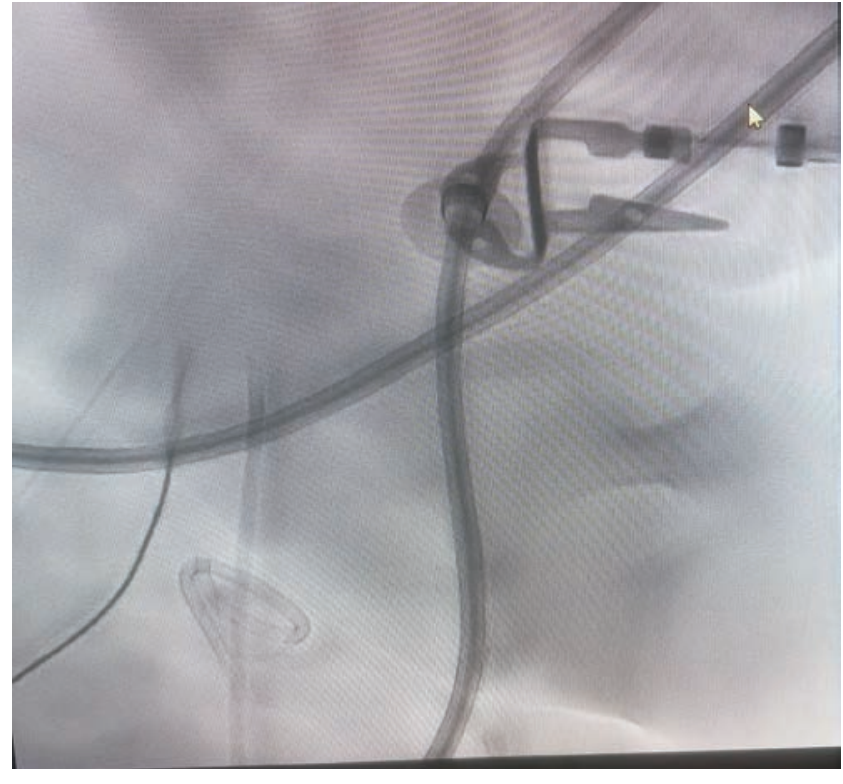

Figure 4. Tried with a rotation of a vascular catheter with a pigtail curve around it. 


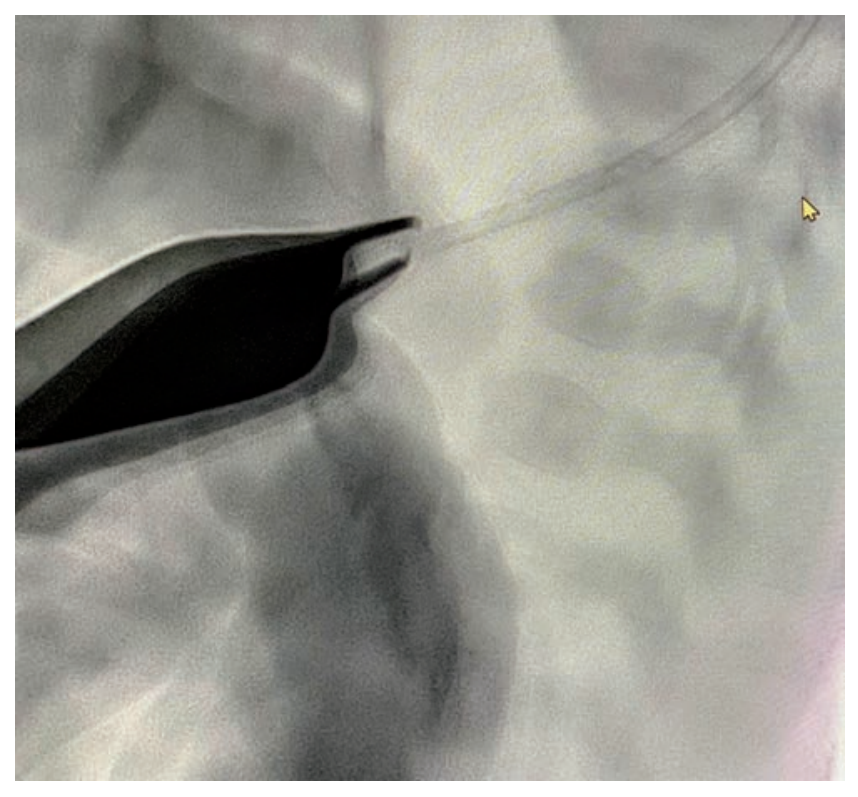

Figure 5. Extraction with tweezers of foreign body.

like empyema, thromboembolism, intrapleural hemorrhages and bronchopleural fistulas. ${ }^{2-9}$

TIPC use is safe and efficient but certain complications have been described. Catheter fractures can be avoided by performing a careful removal, using less traction force. ${ }^{9}$

At present, the use of other less invasive techniques for removing the ruptured TIPC is being considered. Experience in interventional radiology techniques in pediatrics is usually limited to those performed in the adult population. Some pediatric diseases benefit from interventional procedures at different levels: gastrointestinal, genitourinary, cardiovascular, locomotor system, central nervous system, and respiratory. In this last one stated, image-guided biopsies, localization of pulmonary metastases with a hookwire, and placement of tracheal and bronchial stents are usually performed.

The extraction with interventional radiology of the foreign body is guided by an ultrasound and fluoroscopy, as is the case we exposed. Success rates up to $88 \%$ have been reported with experienced hands. 10

\section{References}

1. Moro Serrano M, Vento Torres M. De guardia en neonatología. 3rd ed. España: Editorial Médica Panamericana S.A.; 2016: pp. 781-6.

2. Martinon Torres F, Martinon Sanchez JM. Toracocentesis y drenaje pleural. Ann Pediatr Contin 2003;1:159-5.

3. Solís Sánchez G, Mantecón Fernández L. Tratamiento de los

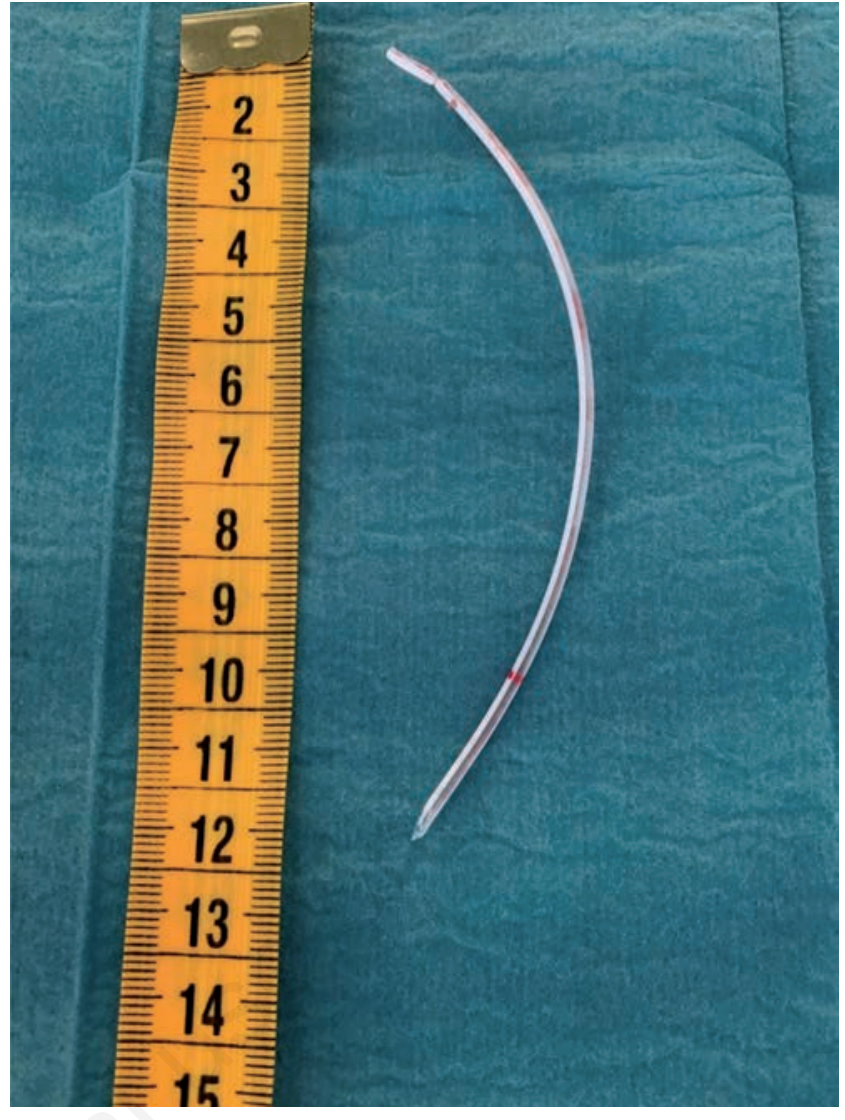

Figure 6. Fractured catheter.

escapes aéreos en Neonatología. Ann Pediatr Contin 2013;11: 350-3.

4. Navarro-Mingorance A, Reyes-Dominguez SB, León-León MC, Pastor-Vivero MD. Rotura de catéter pleural: presentación de 2 casos. Ann Pediatr 2014;80:125-6.

5. Fysh ET, Wrightson JM, Lee YCG, Rahman NM. Fractured indwelling pleural catheters. Chest 2012;141:1090-4.

6. Gaucher A, Levrat Q, Troitzky A, et al. Broken chest tube into the pleural cavity by a Monod' trocar. Ann Fr Anesth Reanim 2010;29:153-3.

7. Canals Candela FJ, Vizcaíno Díaz C, Ferrández Berenguer MJ, et al. Surfactant replacement therapy with a minimally invasive technique: Experience in a tertiary hospital. Ann Pediatr 2016;84:79-84

8. Moe M, Hussain A. Broken chest tube: a rare complication from use of Bonanno catheter for drainage of a malignant pleural effusion. Clin Oncol (R Coll Radiol). 2003;15:220.

9. Fysh ET, Wrightson JM, Lee YCG, Rahman NM. Fractured indwelling pleural catheters. Chest 2012;141:1090-4.

10. Bradley M. Image-guided soft-tissue foreign body extraction: Success and pitfalls. Clin Radiol 2012;6:531-4. 